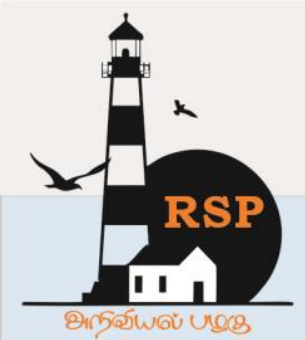

\title{
STERILOID: Room Sanitization Robot
}

Gayathri N Shenoy ${ }^{1}$, Chithu Rajan ${ }^{2}$, Shibi Varghese ${ }^{3}$,Vignesh M.V ${ }^{4}, M s . M$. ShanmugaPriya ${ }^{5}, M s$. Priya $S^{6}$, Ms. Aparna George ${ }^{7}$,

\section{${ }^{1,2,3,4,}$ Student, Applied Electronics and Instrumentation, Affliated to APJ Abdul Kalam Technological}

Univertiy, Approved b y AICTE, Rajagiri School of Engineering and Technology

${ }^{5,6,7}$ Assitant Professor, Applied Electronics and Instrumentation, Affliated to APJ Abdul Kalam

Technological Univertiy, Approved b y AICTE, Rajagiri School of Engineering and Technology

Kochi, Kerala, India.

priyams@rajagiritech.edu.in ${ }^{6}$

\begin{abstract}
In this paper we have proposed a room sanitation robot. The world around us is facing new threats day by day, latest being the corona virus. Social distancing, wearing masks, sanitizing the hands and disinfecting rooms are some precautionary measures to be taken against this deadly virus. Hence our project aims at disinfecting the rooms by deploying robots instead of manpower. Steriloid is a sanitizing robot which can be used to sanitize rooms, pathways, roads etc. It can be controlled in two modes manually or automatically. In the Automatic mode, the robot moves around the room with the help of two ultrasonic sensors. The sensors detect the obstacle while the robot is in motion and control the robot accordingly. In the Manual mode, complete control of the robot is in the user's hands. A mobile application is used to control the robot via a Bluetooth module. So the robot can move to any location. Sanitizer or sanitizing liquid is filled inside a reservoir and a pump is placed inside it. When the robot starts moving, the pump can be turned on from the mobile or manually and it starts sanitizing the room.
\end{abstract}

Keywords-Steriloid, sanitizing robot, automatic mode, manual mode, ultrasonic sensors, Bluetooth module (key words)

\section{Introduction}

Our world is witnessing an evolution where technology is advancing in all sectors of life. Robots are replacing manpower in hazardous and repetitive tasks. Industries use line follower robots to transfer goods from one location to another. Hospitals use robots to perform surgeries and carry medical equipment [10]. Hence robots carry out tasks accurately and thus, they save a lot of time. Every year has few defining moments, but this year has contained so many world changing incidents and one among them is the outbreak of the novel corona virus. As corona virus is an infectious disease it is necessary to take adequate precautions to ensure our safety. Due to the huge rise in the cases of corona virus, to reduce the chances of being infected we should take some precautions. The suggestion from current scenario is that SARS-CoV-2 are alive for hours to days on various surfaces. Therefore, self-sanitization and disinfecting the room is very essential. Hence, we developed a sanitizing robot, Steriloid. Steriloid is aimed at disinfecting the rooms and thereby reducing the spread of the corona virus to an extent. It is a sanitizing robot which can be used to 


\section{www.rspsciencehub.com}

disinfect the room both manually and automatically. This project aims to lower the spread of corona virus to an extent. IoT (Internet of Things) has become one of the most important technologies which has paved way to make people's lives easier and smarter. Bluetooth technology has enabled people to connect their cell phones with almost all devices and appliances. We have incorporated this technology to control our robot.

\section{Proposed System}

As we have discussed above the robot is used to sterilize a room. It can be operated in two modes automatic or manual.

\subsection{Automatic operation}

Automatic mode is implemented by using two ultrasonic sensors [1]; one located in the front while the other on the right side of the robot. While operating in automatic mode the robot covers the room in anticlockwise direction, maintaining a certain distance from the walls of the room.

The electrical signal is converted into acoustic waves using an ultra-sonic sensor. To measure the distance, microcontroller sends a trigger signal to the ultrasonic sensors. Once the ultrasonic sensor is triggered it produces acoustic wave bursts and initiates the time counter. The timer stops when the ultra-sonic sensor receives the reflected signal. A high pulse with same duration as the time difference between the transmitted ultrasonic burst and the received echo signal is the output of the ultrasonic sensor.

Distance $=$ time taken $*$ speed of sound $/ 2$

Table. 1. Shows the logic used to control the direction of the robot.

\begin{tabular}{|l|l|l|}
\hline U1 & U2 & Movement \\
\hline 0 & 0 & Right turn \\
\hline 0 & 1 & Straight \\
\hline 1 & 0 & Left turn \\
\hline 1 & 1 & Left turn \\
\hline
\end{tabular}

Consider table 1. 0 indicates that there is no object in front of the robot and 1 indicates there is object in front of the robot. U1 is the ultrasonic sensor
Volume 02 Issue 08 August 2020

located in front of the robot while U2 is the other ultrasonic sensor located at the right side of the robot.

Now considering the logic given above, if there is no obstacle in front as well as to the right of the robot, the robot will take a right turn. Example of such case is while covering a table that is placed to left of the robot motion and front as well as the right side is free of obstacles. If there is no obstacle in front of the robot and there is obstacle in the right side of the robot the robot will go straight. The robot maintains a specific distance from the wall of the room while covering the room. If there is an obstacle in front of the robot and there is no object in the right side of the robot it takes a left turn.

Each ultrasonic sensor has four pins one for VCC, ground, trigger, and echo. We have two ultrasonic sensors and its VCC and ground pins are connected to Arduino. The trigger and echo pins are connected to the digital pins of the Arduino.Figure.1

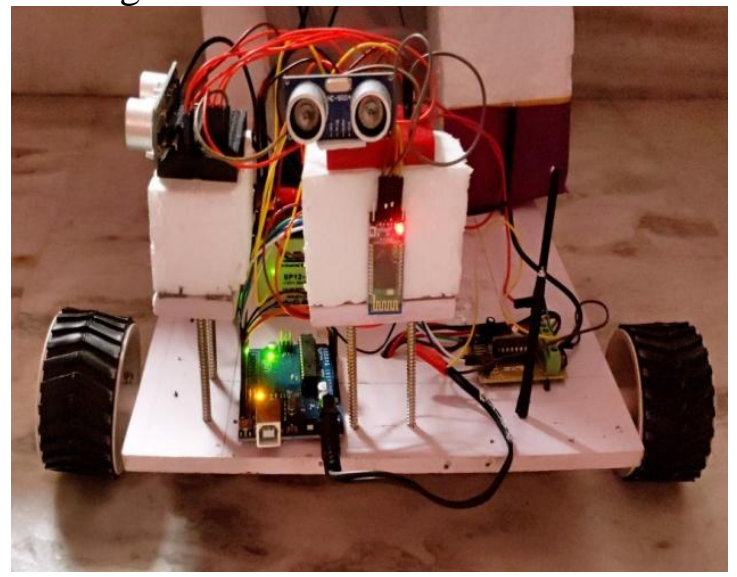

Figure. 1. Ultrasonic sensor connected to the

\subsection{Manual operation}

In manual mode the complete control of the robot is in our hand. The device should be able to communicate with devices like laptop, mobile phone etc. Here we use bluetooth to communicate with the robot.

\subsection{Bluetooth connectivity}

A high power and high-speed Bluetooth technology is designed for the connection between 
any portable equipment. Bluetooth transmission covers about 10 meters (30 feet)

The communication module HC-05 and HC-06 are the common modules available in the market. They are used to control a remote microcontroller device via Bluetooth. Serial communication is enabled with USART using microcontroller.

HC-05 module is used in both master and slave configuration. HC-05 has red LED which indicates connection status of the device. Once it is connected its blinking slows down. It needs $3.3 \mathrm{~V}$. An application is used to pair the device. Once paired it can send data from smart phone to the Bluetooth module, seen on Arduino serial monitor.

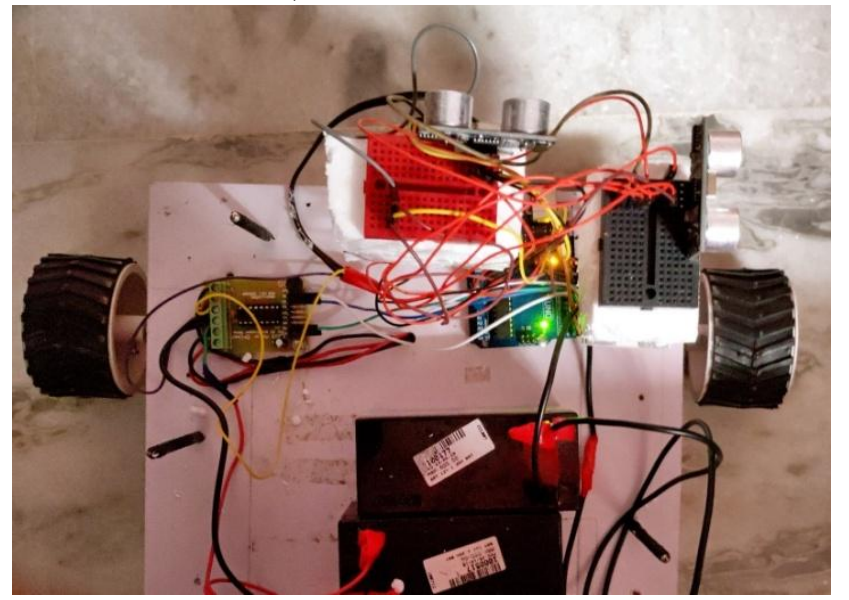

Figure.2. Battery, Motor driver, and Bluetooth module interface with Arduino

The connection of the setup is as follows:

VCC and ground pins are connected to Arduino. TX and RX pins of Bluetooth are connected to digital pins of Arduino. Positive and negative terminals of the motor are connected to motor driver. The A, B, C, D pins of the motor driver are connected to the digital pins of the Arduino.

\subsection{Spraying mechanism}

The pump motor is turned on using a separate switch. Two $6 \mathrm{~V}$ immersive type pumps is used for pumping the sanitizing fluid towards the sprayer. The main reservoir for the sanitizing fluid is placed at the bottom of the robot[1]. The pumps are placed at the bottom of the reservoir. The nozzle can be adjusted to regulate the size of the spraying droplet Figure.3.

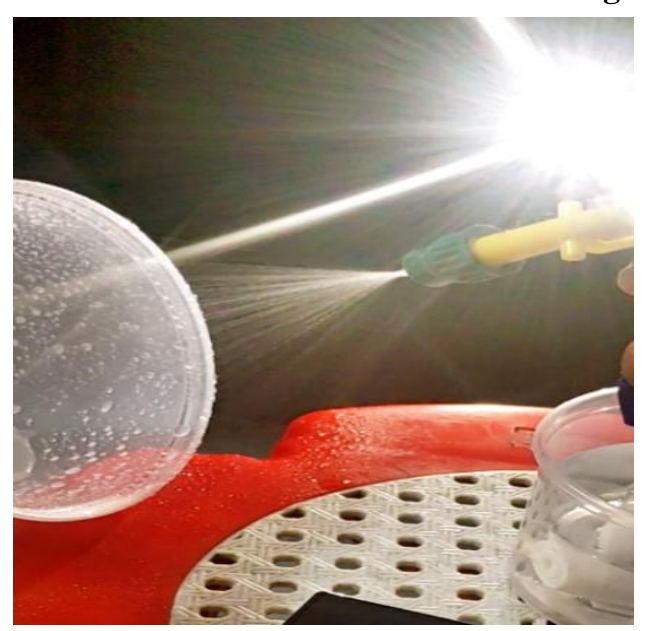

Figure. 3 Shows how the sanitizing fluid is sprayed.

III. Bluetooth Controlled Application

The MIT app inventor is used for designing our project. It is a web application, maintained by the Massachusetts Institute of Technology (MIT).

This app programming is done by a simple drag and drop block. Hey Applications, are developed for Android phones using a web browser and either a connected phone or emulator.

The two main editors of MIT App Inventor are design editor and blocks editor [2] [3]. The design editor is a drag and drop interface. The block editor is an environment in which app inverter can visually layout the logic of apps, to describe the program. To aid in development and testing, App Inventor provides a mobile app called the App Inventor Companion that developers can use to test and adjust the behavior of their apps in real time.

\subsection{Application inventor designer editor}

Application inventors drag components out from the palette (far left) to the viewer (center left) to add them to the app. Inventors can change the properties of the components

(far right) figure.4. An overview of the screen components and project media are also displayed (center right) Properties are used to change the properties of components (size, color etc). The app includes buttons:

- To connect the phone to the Bluetooth module.

- To move the robot forward, left etc.

- To change the mode between manual and automatic.

- To turn on and off the pump motor. 


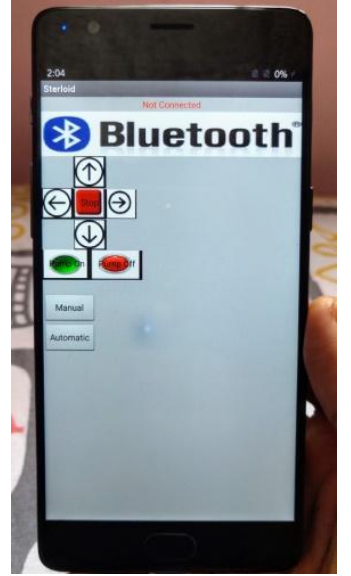

Figure. 4. Steriloid Application

\subsection{App inventer block editor}

In MIT App Inventor, users code application behavior using a block-based programming language. Built-in blocks and component blocks are the two types of blocks in app invertor. Built in blocks library provides basic operations like Strings, numbers, lists, Booleans, mathematical operators etc. Component blocks are used to respond to the system, interact with device hardware, adjust the behavioral and visual aspects of components. The App Inventor servers store the work and help us to keep a track of our projects. Once the app is built, the APK ready to install is sent to the phone and the app is installed.

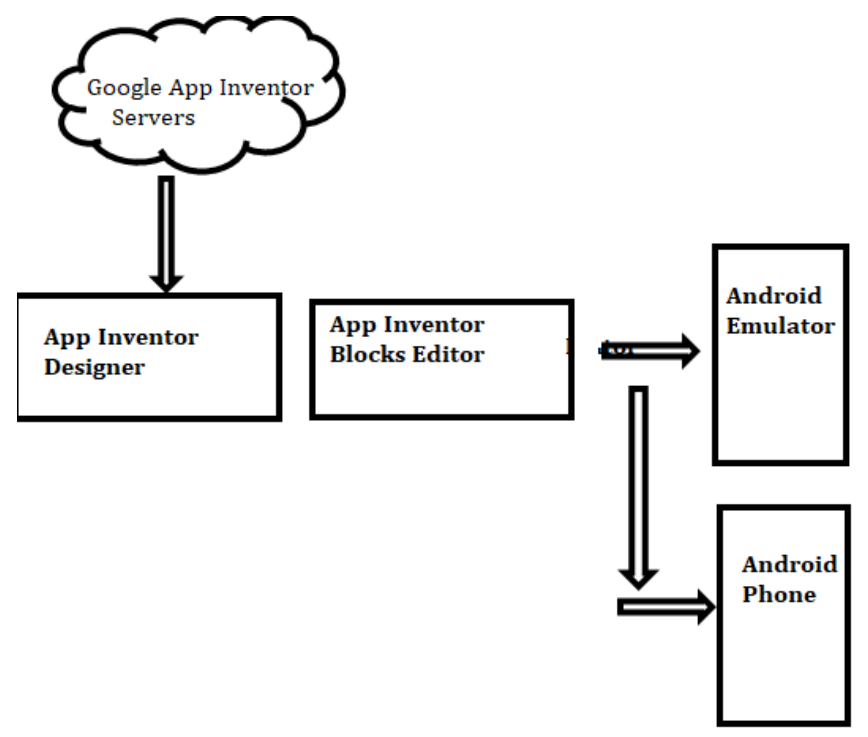

Figure. 5. Application development interface

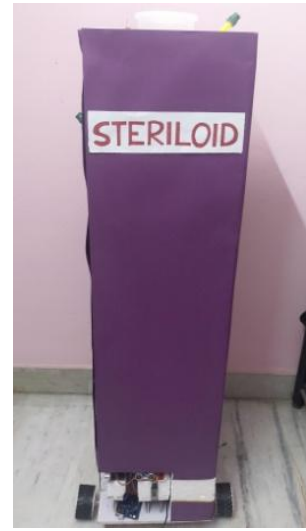

Figure 6: STERILOID

\section{Conclusion \& Future Scope}

Transmission of corona virus occurs through respiratory droplets and through various medium of objects and surfaces like toys, doorknobs, keyboards etc. Vaccine for the virus is in its experimental stage. Since it is a deadly virus to reduce the spread of infection it is better to deploy robots instead of manpower. We have successfully developed the Steriloid in which we can choose it to work in both automatic and manual mode.

The implementation of our project Steriloid was a grant success and beyond our expectation. We are sure that in the present scenario our robot will be an asset to the society and preventing the spread of the deadly disease.

In future our robot can be used in the medical field to carry medicine to different locations of the hospitals and patients by incorporating GPS module. So that it will be extremely helpful in the hospitals as they can reduce the workload of medical staffs [4][5][9][12]. A microphone can be attached to the robot to record the voice of the patients when required [7]. A temperature and pressure sensor can be connected to the robot to measure the temperature and pressure of patients [5][6]. Also, a camera can be added to monitor the patients [3][4][6]. A GSM module can be added to the system so that a doctor can be contacted in case of an emergency [7]. Since the corona virus remains in the air for a period an ozone tube can be installed to kill the viruses. 


\section{www.rspsciencehub.com}

Our robot can also be used in agricultural field to spray pesticides in diseased plants by identifying the pests and infected plant parts using image processing techniques [3][8][11].

We are sure that our project can bring advancements in the field of medicine and Agriculture. We hope our Steriloid will be especially useful in this pandemic situation as it will lower the risk of spreading the virus. Our project aims at betterment of the world.

\section{References}

[1].Ege Ozgul,Ugur Celik "Design and Implementation of Semi-autonomous Antipesticide Spraying and Insect Repellent Mobile Robot for Agricultural Applications"in 2018 5th International Conference on Electrical and Electronic Engineering(ICEEE).

[2].Patton E.W., Tissenbaum M., Harunani F. (2019) MIT App Inventor: Objectives, Design, and Development. In: Kong SC., Abelson H. (eds) Computational Thinking Education. Springer, Singapore

[3].Pvr Chaitanya, Dileep Kotte, A. Srinath, K. B. Kalyan,"Development of Smart Pesticide Spraying Robot",International Journal of Recent Technology and Engineering (IJRTE) ISSN: 2277-3878, Volume-8 Issue-5, January 2020

[4].S. Mahajan and C. M. Vidhyapathi, "Design of a medical assistant robot," 2017 2nd IEEE International Conference on Recent Trends in Electronics, Information \& Communication Technology (RTEICT), Bangalore, 2017, pp. 877-881, doi: 10.1109/RTEICT.2017.8256723.

[5].K, Lakshmi Narayanan and Kumaran, Dr. N. Muthu and G, Rajakumar and Arshadh, Hameedhul and I, Dinesh and V, Caleb, Design and Fabrication of Medicine Delivery Robots for Hospitals (August 5, 2019). Proceedings of International Conference on Recent Trends in Computing, Communication \& Networking Technologies (ICRTCCNT) 2019

[6].Binu K Nair, S.S. Lokhande, "Patient Monitoring System Using Image Processing", International Journal of Advanced Research in Electrical Electronics and Instrumentation Engineering,ISSN : 2278 - 8875,Vol. 6, Issue 6, June 2017
Volume 02 Issue 08 August 2020

[7]. Mohammed Baqer M. Kamel, Loay E. George,"Remote Patient Tracking and

[8]. Monitoring System"inInternational Journal of Computer Science and Mobile Computing,ISSN 2320-088X,Vol. 2, Issue. 12, December 2013, pg. 88 - 94

[9].P. Rajan, B. Radhakrishnan and L. P. Suresh, "Detection and classification of pests from crop images using Support Vector Machine," 2016 International Conference on Emerging Technological Trends (ICETT), Kollam, 2016, pp. 1-6, doi: 10.1109/ICETT.2016.7873750.

[10].S. Jeon and J. Lee, "The simulator for performance analysis of multiple robots for hospital delivery," 2016 13th International Conference on Ubiquitous Robots and Ambient Intelligence (URAI), Xi'an, 2016, pp. 746-748, DOI: 10.1109/URAI.2016.7734105.

[11].Garmann-Johnsen, Niels \&Mettler, Tobias \&Sprenger, Michaela. (2014). Service Robotics in Healthcare: A Perspective for Information Systems Researchers? 10.13140/2.1.4973.9203.

[12].Rupesh G. Mundada, Dr. V. V. Gohokar,"Detection and Classification of Pests in Greenhouse Using Image Processing" in IOSR Journal of Electronics and Communication Engineering (IOSR-JECE) eISSN: 2278-2834,p- ISSN: 2278-8735. Volume 5, Issue 6 (Mar. - Apr. 2013), PP 5763

[13].B. Krishnamurthy and J. Evans, "HelpMate: A robotic courier for hospital use," [Proceedings] 1992 IEEE International Conference on Systems, Man, and Cybernetics, Chicago, IL, USA, 1992, pp. 1630-1634 vol.2, DOI: 10.1109/ICSMC.1992.271504. 